tuberculosis prevention: a decision analysis addressing inoculation of US house officers in the light of multiple drug-resistant strains. $A m \mathcal{F}$ Resp Crit Care Med 1994; 149 (II): A855 (abstr).

16 Torres M, Mendez-Sampeiro P, Jimenez-Zamudio L, et al.

Comparison of the immune response against Mycobacterium tuberculosis antigens between a group of patients with active pulmonary

tuberculosis and healthy household contacts. Clin Exp Immunol 1994; 96: 75-78.
17 Kashala O, Marlınk R, Ilunga $M$, et al. Infection with human immunodeficiency virus type 1 (HIV-1) and human $T$ cell

lymphotropic viruses among leprosy patients and contacts: correlation between HIV-1 cross-reactivity and antibodies to lipoarabinomannan. J Infect Dis 1994; 169: 296-304.

18 Shattock RJ, Friedland JS, Griffin GE. Phagocytosis of Mycobacterum tuberculosis modulates human immunodeficiency virus replication in human monocytic cells. F Gen Virol 1994; 75: 849-56.

COMMENTARY

\section{Myocardial infarction: ACE inhibitors for all? for ever?}

The beneficial, life-saving effect of angiotensin converting enzyme (ACE) inhibition in patients with signs of impaired cardiac function early after myocardial infarction was shown by the AIRE study. ${ }^{1}$ At an average follow-up of 15 months, mortality was $23 \%$ in 982 patients in the placebo group vs $17 \%$ in 1004 patients in the ramipril group. In this study ramipril was started between 3 and 10 days after infarction. More recently GISSI-32 showed that treatment with an ACE inhibitor immediately after hospital admission was beneficial when given to all patients with myocardial infarction. In GISSI-3, mortality at 6 weeks was $7 \cdot 1 \%$ in 9460 open controls vs $6.3 \%$ in 9435 patients receiving oral lisinopril. These observations are supported by preliminary data from ISIS-4, which has been reported, ${ }^{3}$ but not yet published, but contrast with the absence of any mortality benefit in patients treated with intravenous and oral enalapril in the 6090 patients in the CONSENSUS-II study.

So, should all patients with myocardial infarction receive an ACE inhibitor immediately, or should such therapy be initiated later in selected patients? To resolve this question several issues have to be addressed, including the pathophysiology of ACE inhibition during and after myocardial infarction and the differences between the trials. In any event, treatment with an ACEinhibitor, once started in patients with heart failure or left ventricular dysfunction, should be continued indefinitely since long-term beneficial effects from such therapy have been shown in several large trials. ${ }^{1,5-7}$

Survival after myocardial infarction is determined predominantly by residual left ventricular function, ${ }^{8}$ which is the result of three distinct but overlapping pathophysiological processes: (a) the initial loss of myocytes (infarct size); (b) subsequent stretching and thinning of the infarcted segment during the first few days (infarct expansion); and (c) further remodelling of both infarcted and non-infarcted myocardium over several months.

Attenuation of the ischaemic insult by captopril was observed in a pig model of coronary occlusion and reperfusion. ${ }^{9}$ By comparison with saline, release of creatine kinase, inosine, and noradrenaline was reduced by the ACE inhibitor. In a rat model captopril, but not enalapril, reduced ventricular fibrillation upon reperfusion. ${ }^{10}$ In another rat model, ${ }^{11}$ captopril during 1-21 days after coronary artery ligation did not reduce infarct size, whereas enalapril has been observed to limit infarct size in rats. ${ }^{12}$ In a study in which infarct size was measured by serial enzyme determinations in 298 patients with a first anterior infarction treated with streptokinase and either captopril or placebo, ${ }^{13}$ a $15 \%$ limitation of size was reported in those with a large infarct, but differences in the whole group were not statistically significant. Moreover, left ventricular ejection fraction after 3 months was the same (44\%) in the placebo and captopril groups. ACE inhibitors have strong neurohumoral effects: apart from suppressing plasma angiotensin converting enzyme activity, they lower plasma noradrenaline and increase plasma renin activity in patients with myocardial infarction. ${ }^{13,14}$ Systemic blood pressure is reduced with the first dose, ${ }^{13}$ but the effect on infarct size in clinical practice is uncertain. Unfortunately measurement of infarct size was not included in some of the patients in CONSENSUS-II and GISSI-3.

All studies in which echocardiography or ventriculography was used point to the preservation of left ventricular function by ACE inhibition in patients with large infarcts. ${ }^{13,16-20}$ Nevertheless, most series were small and the data were often not significant within the study. ${ }^{13,19}$ Several groups have analysed the time-course of global and regional left ventricular function, showing that both infarct expansion and remodelling can be attenuated by ACE inhibitors. For example, in the Glaswegian study ${ }^{17}$ there was a significant increase in the length of the infarct-related left ventricular segment after 2 months in the placebo group, with smaller changes after captopril. About half this effect was already apparent at day 3 and day 7. Similarly beneficial effects of captopril on left ventricular end-diastolic volume, end-systolic volume, and ejection fraction were apparent after 7 days in a New Zealand study. ${ }^{18}$

One way to examine the different outcomes of GISSI-3 and CONSENSUS-II would be a statistical approachcombination of all mortality data of these studies and of ISIS-4 and the smaller studies in a single analysis. In such an analysis, GISSI-3 and ISIS-4 would dominate and there would be an overall beneficial effect of immediate ACE inhibition in all patients with evolving infarction. However, this strategy does not really explain the differences between trials, and physicians who want to select the best treatment for individual patients are bound to remain bewildered.

There are important differences between the studies as shown in the table. In CONSENSUS-II there were more elderly patients, fewer women, and more patients with a previous infarction. In GISSI-3 more patients were treated within 12 hours of symptom onset, and more patients received thrombolytic therapy. Few data on specific patient subgroups have been presented, so we do not know whether these differences can explain the differences in outcome between the two trials. In CONSENSUS-II there was some excess mortality in elderly patients receiving enalapril, but this was not confirmed in GISSI-3. 


\begin{tabular}{|c|c|c|c|c|}
\hline & \multicolumn{2}{|c|}{ CONSENSUS II } & \multicolumn{2}{|l|}{ GISSI-3 } \\
\hline & Placebo & Enalapril & Controls & Lisinopril \\
\hline Patients (n) & 3046 & 3044 & 9453 & 9435 \\
\hline Age $>70(\%)$ & 41 & 42 & 27 & 27 \\
\hline Females (\%) & 16 & 17 & 22 & 22 \\
\hline Previous infarction (\%) & 24 & 23 & 14 & 14 \\
\hline Previous angina (\%) & 39 & 37 & 34 & 34 \\
\hline \multicolumn{5}{|l|}{ Site of infarct* } \\
\hline Anterior (\%) & 41 & 42 & 28 & 27 \\
\hline Inferıor (\%) & 34 & 33 & 32 & 32 \\
\hline Multiple (\%) & $\cdots$ & . & 3 & 3 \\
\hline Q-wave (\%) & 59 & 58 & 64 & 63 \\
\hline \multicolumn{5}{|l|}{ Clinical presentation $\dagger$} \\
\hline$h$ after symptom onset & 15 & 15 & \multicolumn{2}{|c|}{$6-12$} \\
\hline Heart rate & 75 & 75 & \multicolumn{2}{|c|}{$60-79$} \\
\hline Systolic pressure & 134 & 133 & \multicolumn{2}{|c|}{$121-150$} \\
\hline \multicolumn{5}{|l|}{ Other treatment } \\
\hline Beta-blockers (\%) $\ddagger$ & 67 & 66 & 31 & 30 \\
\hline Thrombolytic (\%) & 56 & 56 & 72 & 71 \\
\hline
\end{tabular}

*Infarct site reported for all patients in CONSENSUS-II and in those with Q-waves only in GISSI-3.

†CONSENSUS-II reported mean values and GISSI-3 the distribution in certain ranges; in the table the range including the median value is presented.

$\ddagger$ Any beta-blockers before randomisation (CONSENSUS-II) or intravenous beta-blockers only (GISSI-3)

\section{Table: Comparison of selected baseline characteristics in two} trials of immediate ACE inhibition in myocardial infarction

Different ACE inhibitors were studied-enalapril in CONSENSUS-II and lisinopril in GISSI-3- but I am not aware of pharmacological differences between these two drugs that could explain different outcomes. Both drugs have a plasma half-life of about 12 hours. However, the mode of administration differed considerably. Enalapril was initiated with a 2-hour intravenous infusion followed by ascending oral dosing; most patients (82\%) reached the target dose of $20 \mathrm{mg} /$ day on day 10 . Lisinopril was given orally and only $48 \%$ of patients received the full dose of $10 \mathrm{mg} /$ day. The more rapid intravenous administration of enalapril resulted more frequently in hypotension: $12 \%$ in CONSENSUS-II vs $9 \%$ in GISSI- 3 with blood pressure less than $90 \mathrm{~mm} \mathrm{Hg}$. This fall in pressure may have led to increased mortality in CONSENSUS-II, as has already been suggested by the investigators $^{4}$ and this might have offset a potential beneficial effect of the drug.

Immediate intravenous administration of an ACE inhibitor carries a risk for hypotension, especially if the drug is given in combination with streptokinase. ${ }^{21}$ However, such immediate administration would be warranted if it resulted in myocardial salvage. Since limitation of infarct size has not been shown unequivocally, it seems prudent to avoid immediate ACE inhibition for the time being.

Improved survival with ACE inhibition in patients with myocardial infarction seems to be due to attenuation of infarct expansion and remodelling. Accordingly, treatment will be most effective in patients at risk for such changes, during the period at which these processes evolve. Thus treatment in appropriate patients should be started early - within a few days, but not necessary immediately after hospital admission.

If a decision has been made to give an ACE inhibitor, a low oral dose should be given first. Intravenous administration seems unnecessary and possibly harmful. ${ }^{*}$ Once started, the therapy can be continued indefinitely, unless side-effects or contraindications develop.

Patients at risk for significant infarct extension and remodelling are those with larger infarcts, so it is logical to select such patients for ACE-inhibition. The AIRE study specifically selected patients with clinical signs of impaired cardiac function and showed a $27 \%$ relative risk reduction (absolute mortality benefit $6 \%$ ). The smaller $(12 \%$ relative or $0.5 \%$ absolute) reduction in GISSI-3 might reflect a combination of a bigger effect in patients with larger infarcts and heart failure and a smaller or no effect in those with a small infarct. Indeed, GISSI-3 patients in Killip class 2 or greater had a 3\% mortality benefit $v s$ only $0 \cdot 3 \%$ in patients without heart failure (Killip class 1) at admission..$^{22,23}$ Additional subgroup analyses of GISSI-3, and possibly ISIS-4, are eagerly awaited to assess which patients really benefit from early ACE inhibition.

\section{Maarten L Simoons}

Thoraxenter, Erasmus University, Rotterdam, Netherlands

1 The Acute Infarction Ramipril Efficacy (AIRE) Study Investigators. Effect of ramipril on mortality and morbidity of survivors of acute myocardial infarction with clinical evidence of heart failure. Lancet 1993; 342: 821-28.

2 GISSI-3: effects of lisinopril and transdermal glyceryl trinitrate singly and together on 6-week mortality and ventricular function after acute myocardial infarction. Lancet 1994; 343: 1115-22.

3 ISIS-4 Collaborative Group. Fourth International Study of Infarct Survival: protocol for a large simple study of the effects of oral mononitrate, of oral captopril and of intravenous magnesium. $A m \mathfrak{f}$ Cardiol 1991; 68: 87D-100D.

4 Swedberg K, Held P, Kjekshus J, Rasmussen K, Ryden L, Wedel H, on behalf of the CONSENSUS II Study Group. Effects of the early administration of enalapril on mortality in patients with acute myocardial infarction. Results of the Cooperative New Scandinavian Enalapril Survival Study (CONSENSUS). $N$ Engl f Med 1992; 327: 678-84.

5 The CONSENSUS Trial Study Group. Effects of enalapril on mortality in severe congestive heart failure: results of the Cooperative North Scandinavian Enalapril Survival Study (CONSENSUS). $N$ Engl f Med 1987; 316: 1429-35.

6 Pfeffer MA, Braunwald E, Moyé LA, et al. Effect of captopril on mortality and morbidity in patients with left ventricular dysfunction after myocardial infarction. $N$ Engl f Med 1992; 327: 369-77.

7 The SOLVD Investigators. Effect of enalapril on survival in patients with reduced left ventricular ejection fractions and congestive heart failure. N Engl f Med 1991; 325: 293-302.

8 Simoons ML, Vos J, Tijssen JGP, et al. Long term benefit of early thrombolytic therapy in patients with acute myocardial infarction: 5 year follow up of a trial conducted by the Interuniversity Cardiology Institute of the Netherlands. $\mathcal{F A C C} 1989 ; 14: 1609-15$.

9 de Graeff PA, van Gilst WH, Bel K, de Langen CDJ, Kingma JH, Wesseling $\mathbf{H}$. Concentration-dependent protection by captopril against myocardial damage during ischemia and reperfusion in a closed chest pig model. 7 Cardiovasc Pharmacol 1987; 9 (suppl 2): S37-42.

10 van Gilst WH, de Graeff PA, Wesseling $\mathbf{H}$, de Langen CDJ. Reduction of reperfusion arrhythmias in the ischemic isolated rat heart by angiotensin converting enzyme inhibitors: a comparison of captopril, enalapril, and HOE 498. F Cardiovasc Phamnacol 1986; 8: 722-28.

11 Schoemaker RG, Debets JJM, Struyker-Boudier HAJ, Smits JFM. Delayed but not immediate captopril therapy improves cardiac function in conscious rats, following myocardial infarction. $\mathcal{F ~} \mathrm{Mol} \mathrm{Cell}$ Cardiol 1991; 23: 187-97.

12 Hock CE, Ribeiro LGT, Lefer AM. Preservation of ischemic myocardium by a new converting enzyme inhibitor, enalaprilic acid, in acute myocardial infarction. Am Heart $\mathcal{f} 1985 ; 109: 222-28$.

13 Kingma JH, van Gilst WH, Peels $\mathrm{CH}$, et al. Acute intervention with captopril during thrombolysis in patients with first anterior myocardial infarction. Results from the Captopril and Thrombolysis Study (CATS). Eur Heart $\mathcal{f}$ (in press).

14 Sigurdsson A, Held P, Andersson G, Swedberg K. Enalaprilat in acute myocardial infarction: tolerability and effects on the renin-angiotensin system. Int $\mathcal{F}$ Cardiol 1991; 33: 115-24.

15 Sharpe N, Murphy J, Smith H, Hannan S. Treatment of patients with symptomless left ventricular dysfunction after myocardial infarction. Lancet 1988 ; i: $255-59$.

16 Pfeffer MA, Lamas GA, Vaughan DE, Parisi AF, Braunwald E. Effect of captopril on progressive ventricular dilatation after anterior myocardial infarction. $N$ Engl $\mathscr{f}$ Med 1988; 319: 80-86. 
17 Oldroyd KG, Pye MP, Ray SG, et al. Effects of early captopril administration on infarct expansion, left ventricular remodeling and exercise capacity after acute myocardial infarction. Am $f$ Cardiol 1991 68: $713-18$

18 Sharpe N, Smith H, Murphy J, Greaves S, Hart H, Gamble G. Early prevention of left ventricular dysfunction after myocardial infarction with angiotensin-converting-enzyme inhibition. Lancet 1991; 337: 872-76.

19 Nabel EG, Tpol EJ, Galeana A, et al. A randomized placebocontrolled trial of combined early intravenous captopril and recombinant tissue-type plasminogen activator therapy in acute myocardial infarction. FACC 1991; 17: 467-73.

20 Bonarjee VVS, Carstensen S, Caidahl K, et al. Attenuation of left ventricular dilatation after acute myocardial infarction by early initiation of enalapril therapy. Am F Cardiol 1993; 72: 1004-09,

21 Kingma JH, van Gilst WH, de Graeff PA, Louwerenburg HW, Six AJ, Wesseling $\mathrm{H}$. Captopril during thrombolysis in acute myocardial infarction: feasibility, tolerance and beneficial neurohumoral effects. In: MacGregor GA, Sever PS, eds. Current advances in ACE inhibition. Edinburgh: Churchill Livingstone, 1989: 291-95.

22 Ball SG, Reynolds GW, Murray AD.. ACE inhibitors after myocardial infarction. Lancet 1994; 343: 1632.

23 Tognoni G. ACE inhibitors after myocardial infarction. Lancet 1994; 343: 1633-34.

\section{Whither cancer centres?}

The consultative document $A$ Policy Framework for Commissioning Cancer Services ${ }^{1}$ recommends the establishment of a hierarchy of cancer centres and units in each National Health Service (NHS) region in England and Wales. Primary care is seen as the focus, and due emphasis is paid to family and psychosocial issues. The report anticipates intense communication and coordination in support of the central theme-namely, that geography should not be a determinant of the quality of cancer treatment. By making these recommendations, the report raises a fundamental issue about the concept of cancer centres. Do such centres meet the need for cancer control; if not, do we need them at all?

The evolution of both medical science and public perception with respect to cancer has been so profound that we tend to forget the original premises (apart from the control of radium) upon which cancer centres were established. 50 years ago the word cancer was enunciated in hushed tones, and for most patients there was little that could be done. Health professionals were uncomfortable talking about cancer, and reticent to assume a substantive treatment role. The few who did formed the small working groups that evolved into the main cancer centres of midcentury. Our predecessors knew little of aetiology or epidemiology, and the focus was treatment of advanced disease. Nevertheless, their efforts earned an almost saintly public esteem, and established the political basis for major public expenditures in cancer treatment and research.

Times have changed. We now understand cancer to be a family of chronic diseases. Although there is a vast array of treatments for most malignant disorders and "breakthroughs" are reported daily, overall death rates have not been much improved. There is public frustration on several counts: lack of progress in treatment, fragmentation of care, inequity of access, and apparent politicisation of pain and suffering. To soothe the public anger and meet the biological need, we need to look at these issues from the broad perspective of cancer control. The goal is to diminish mortality and morbidity and by so doing augment quality of life. From a strategic perspective, the future of cancer control, and of cancer centres, depends on our understanding of its "spectrum"; a method to diffuse effective techniques; and the establishment of a pragmatic, efficient evaluation infrastructure. ${ }^{2}$

Cancer control is not treatment-it is prevention, early diagnosis, treatment, and palliation. Each of these elements is characterised by unique strategies for implementation and evaluation. For example, prevention requires a substantive understanding of aetiology, and its evaluation is incidence-population based. By contrast, palliation is case-centred, and effectiveness is measured by the extent to which symptoms are relieved and quality of life is restored. For each cancer we must target our efforts for maximum effect. Our knowledge of aetiology and the dearth of effective therapy suggests that we should prevent lung cancer rather than emphasise treatment. We should screen for cervical cancer. We should treat lymphomas, childhood tumours, germ-cell tumours, and within limited goals, the overwhelming prevalence of epithelial tumours. From the perspectives of both individual patient and social policy, we have to understand the means and principles of palliation at all stages of disease. Traditional cancer centres tend to focus on treatment to the exclusion of other elements.

Diffusion of technology is the second perspective of cancer control. We tend to think in institutional terms rather than by jurisdiction. There is a tendency to centralise new therapies out of concern for safety, cost, and research priority. Yet if one quarter or more of the population is destined to develop a treatable chronic disease, free-standing cancer centres will either become parallel health systems, which we cannot afford, or will implode under the load, thereby compromising the specialised insight and evaluation capacity that represents their raison d'être. Furthermore, the social dislocation inherent in treating a chronic disease at a distant site can be lessened by a distributed delivery system. The question is how to maintain both research and treatment quality. Three principles form the basis of a strategy. The first is to distinguish that which needs to be centralised because it is capital intensive (eg, linear accelerators) from that which is conceptually complex but technologically simple (eg, chemotherapy). The latter can be decentralised safely provided there is adequate information and control. The second principle is to consider the trajectory of an illness as a predictable pathway punctuated by both planned and unplanned decision points, at which multidisciplinary specialist input is required. The third is to acknowledge the skills of the cancer specialist team in the medical aspects of the disease, and of the local physician in the comorbidities and psychosocial dimensions. Our experience over 15 years in Manitoba, Canada, convinces us that community physicians, with expert monitoring and support from a distance, can be trained to recognise decision points, and in this way cancer chemotherapy and follow-up can be safely decentralised. ${ }^{3}$

The essence of future cancer control is not solely a treatment place, but also a jurisdictional information infrastructure; a cancer programme. The key is to establish evidence-based multidisciplinary approaches to each tumour across the cancer spectrum. That means facilitating and paying for experts with ongoing experience to enable them to define and disseminate practical guidelines, and to monitor implementation. It means supporting research, and providing a distributed substantive information infrastructure. There is no 